\title{
Computador-internet nas Práticas de Estudo Contemporâneas: uma Pesquisa com Estudantes de Psicologia
}

Internet-computer in Contemporary Study Practices: a Research with Psychology Students

Ordenador-internet en las Prácticas de Estudio Contemporáneas: una Investigación con Estudiantes de Psicología

Beatriz Sancovschi \& Virgínia Kastrup Universidade Federal do Rio de Janeiro

http://dx.doi.org/10.1590/1982-3703001252012 
Resumo: O artigo objetiva investigar como está sendo realizado o estudo na contemporaneidade. Segue dois caminhos. Inicialmente opera uma inflexão no campo dos estudos sobre o estudo. Ao invés de conceber o estudo como entidade objetiva e naturalizada propõe, com a ajuda das abordagens construtivistas da cognição, como as de J. Piaget, L.Vigotski, F. Varela e H. Maturana e dos trabalhos de M. Foucault e R. Chartier, analisar o problema a partir da noção de práticas de estudo. O estudo passa a ser resultado das ações concretas dos estudantes, deixando de ser concebido como atividade mental supostamente invariante, voltada para aquisição de um saber. Em seguida, apresenta e discute uma pesquisa de campo, na qual foram entrevistados 15 estudantes de Psicologia do primeiro ao nono período de quatro instituições de ensino superior do município do Rio de Janeiro, sendo duas públicas e duas privadas. As entrevistas seguiram a técnica da entrevista de explicitação. A conclusão aponta para a importância do uso do computador-internet nas práticas de estudo contemporâneas e analisa alguns de seus efeitos, como a grande quantidade de informação, o estudo em circulação, a fragmentação e composição de partes e a coexistência do estudo com o texto digital e impresso.

Palavras-chave: Práticas de estudo. Computador. Novas tecnologias. Subjetividade contemporânea.

Abstract: This paper aims at investigating how study is being accomplished in contemporaneity. It follows two main paths: Initially, it operates an inflection in the study field of studies. Instead of conceiving study as an objective and naturalized entity, it proposes to analyze the issue from notions of practices of study, with the support of constructivist approaches of cognition such as those by J. Piaget, L.Vygotski, F. Varela and H. Maturana, as well as the work of M. Foucault and R. Chartier. The study becomes the result of concrete actions of students, instead of being conceived as an allegedly invariant mental activity aiming at knowledge acquisition. Secondly, it presents and discusses a field research in which fifteen psychology students were interviewed. The interviewees belong to four different institutions from the city of Rio de Janeiro, two public and two private, where they were between the $1^{\text {st }}$ and $9^{\text {th }}$ semesters. Interviews were carried out following the explanation technique. The conclusion points out the importance of the use of internet-computer in contemporary study practices, and analyzes some of its effects, such as the great amount of information, the study in circulation, the fragmentation and composition of parts, and the coexistence of study with the digital and printed texts.

Keywords: Study practice. Computer. New technologies. Contemporary subjectivity.

Resumen: El artículo tiene el objetivo de investigar cómo se realiza el estudio en el mundo contemporáneo. Toma dos caminos: De inicio realiza una inflexión en el campo de los estudios sobre el estudio. En vez de entender el estudio como una entidad objetiva y natural propone, con ayuda de abordajes constructivistas de la cognición como los de J. Piaget, L. Vygotski, F. Varela y H. Maturana, y de los trabajos de M. Foucault, R. Chartier, analizar el problema partiendo del concepto de prácticas de estudio. El estudio empieza a ser entendido como resultado de las acciones concretas de los estudiantes, dejando de ser comprendido como actividad mental supuestamente invariable, orientada para obtener un saber. Después presenta y discute una investigación de campo, en la que se entrevistaron a 15 estudiantes de psicología del $1^{\circ}$ al $9^{\circ}$ período de cuatro universidades de la capital de Río de Janeiro, siendo dos públicas y dos privadas. Las entrevistas siguieron la técnica de entrevista de explicitación. La conclusión indica la importancia del uso del ordenador-internet en prácticas de estudio contemporáneas y analiza algunos de sus efectos: la gran cantidad de informaciones, el estudio en circulación, la fragmentación y composición de partes y la coexistencia del estudio con el texto digital e impreso.

Palabras-clave: Prácticas de estudio. Ordenador. Nuevas tecnologías. Subjetividad contemporánea. 


\section{Introdução}

O presente artigo tem como objetivo investigar as práticas de estudo na contemporaneidade, em que o uso do computador e da internet ocupam lugar de destaque. Ao invés de considerar o estudo como entidade objetiva e naturalizada, trabalharemos com a noção de práticas de estudo. A fundamentação teórica é buscada nas abordagens construtivistas da cognição, como as de Jean Piaget, Lev S. Vigotski, Francisco Varela e Humberto Maturana, bem como nos trabalhos dos historiadores Michel Foucault e Roger Chartier.

A partir da primeira metade do século XX, em função das transformações sociais, políticas e econômicas, o estudo tornou-se alvo de elaborações teóricas e de diversas pesquisas (Ronca, 1982). Tomado na maioria dos casos como objeto natural e unificado, o estudo tem sido investigado principalmente no intuito de proporcionar estratégias que podem ser eficazes para os estudantes. Nesse contexto desenvolveram-se técnicas como a do Estudo Dirigido (Ronca, 1982) e da Instrução Programada (Skinner, 1972). Mais contemporaneamente, o foco tem incidido sobre os processos autorregulatórios e o papel da metacognição. A orientação das pesquisas tem se voltado ao treinamento de estratégias para o desenvolvimento de competências e habilidades autorregulatórias. Como exemplo, citamos os trabalhos de Rosário (2004), Rosário, Nuñez e Pienda (2006), Bilimário e Almeida (2008), Gomes e Torres (2005). Esses baseiam-se, em parte, na herança deixada pelos pesquisadores da Universidade de Gotemburgo (Suécia) que, liderados por Ference Marton, criaram o constructo Students Approaches to Learning. A análise das pesquisas que conduziram à elaboração desse constructo (Marton \& Säaljö, 1976a, b; Marton, Hounsell \& Entwistle, 1997) aponta que havia inicialmente uma atenção às práticas concretas de estudo. No entanto, com o desenvolvimento das pesquisas, a investigação das práticas foi dando lugar a modelos teóricos e formulações gerais como Surface Approach to Learning e Deep Approach to Learning, que passaram a nortear as pesquisas. Nesse contexto, a análise das práticas concretas de estudo passa a ocupar uma posição secundária.
A partir da noção de práticas de estudo, apresentaremos e discutiremos dados recolhidos numa pesquisa de campo em que entrevistamos estudantes de Psicologia de quatro instituições de ensino superior do município do Rio de Janeiro acerca de suas práticas de estudo. As entrevistas seguiram a técnica da explicitação (Vermersch, 2000). Através das falas dos estudantes percebemos que as práticas de estudo contemporâneas são fortemente marcadas pela presença do computador-internet, alterando radicalmente a forma de estudar nos dias atuais e ocupando o lugar antes ocupado por livros e bibliotecas. Em outro artigo discutimos o problema da aprendizagem e das transformações no funcionamento da atenção produzidas por tais práticas e analisamos o quanto $\mathrm{o}$ acoplamento cognição-computador-internet concorre para a produção de uma atenção saltitante e sem ritmo, que se desdobra numa atenção suficiente e dividida (Sancovschi \& Kastrup, 2013). Por outro lado, ressaltamos o quanto tal acoplamento tem possibilitado o surgimento de uma política cognitiva curiosa e desejosa de saber.

\section{Sobre a noção de práticas de estudo}

Para Jean Piaget $(1978,2001)$, é a partir das ações que o conhecimento é construído. As ações são autorreguladas por processos de assimilação, acomodação e equilibração, conduzindo ao desenvolvimento das estruturas da inteligência. Também segundo Lev S. Vigotski $(1998,2000)$ o conhecimento se constrói a partir da ação mediada e dos processos de internalização. A ação mediada é própria dos seres humanos e implica no uso de signos como, por exemplo, a linguagem e/ou instrumentos como lápis, caderno, livro e computador. O processo de internalização consiste numa transformação daquilo que é conhecido, que passa doravante a constituir o sujeito. De acordo com Angel Pino (1992), a internalização deve ser entendida como uma reconstrução no plano pessoal daquilo que antes era do domínio social, ou seja, realizado no encontro com os outros através das mediações. Portanto, para Vygotski (2000), a construção da cognição está atrelada à questão 
do desenvolvimento cultural ${ }^{1}$. Partindo de suas análises, entendemos que quando o objetivo é investigar as práticas de estudo é preciso incluir o problema dos mediadores e os efeitos de transformação cognitiva que deles resultam. Pensando a invenção de novos mediadores, como é o caso do computador-internet, é preciso investigar os efeitos de subjetivação que eles produzem.

Com Humberto Maturana e Francisco Varela, a ideia de conhecimento como ação é levada mais adiante, inicialmente com a formulação da teoria da autopoiese (Maturana \& Varela, 1995) e depois com a abordagem da enação (Varela, 2003; Varela, Thompson \& Rosch, 2003). Podemos sintetizar suas ideias como uma abordagem autopoiética-enativa. Ao invés de entender a cognição como a relação entre um sujeito e um mundo preexistentes, sujeito e mundo passam a ser concebidos como efeitos de práticas cognitivas. Para Maturana e Varela (1995), a atividade de conhecer coloca em cena, a partir da ação, acoplamentos estruturais e breakdowns. Os acoplamentos dizem respeito a modos de interação estabelecidos entre a estrutura do organismo e o meio. Uma vez estabelecidos, produzem variações na estrutura do organismo, criando novas formas de ser, conhecer e estar no mundo. As mudanças estruturais criam novos campos perceptivos que, por sua vez, participarão de novos acoplamentos. Nesse movimento, o breakdown ganha lugar de destaque. O breakdown, por vezes traduzido como colapso (Varela, 2003), é uma perturbação que acontece em função do próprio movimento autopoiético-enativo e coloca em xeque os acoplamentos e modos de funcionar anteriores. Ele é uma espécie de hesitação em relação ao fazer e ao hábito, sendo capaz de instaurar uma diferença, uma bifurcação. Dessa maneira, o breakdown pode possibilitar o aparecimento de novas formas de ser e de conhecer. Seu resultado é sempre imprevisível, não podendo ser determinado nem pelo organismo e nem pelo mundo. Para Maturana e Varela (1995), a construção do conhecimento não possui orientação predefinida, mas segue o caminho traçado no próprio viver-fazer.

Sendo assim, entendemos que tais abordagens construtivistas, na medida em que atribuem importância fundamental às ações no processo de construção da cognição, abrem caminho para o estudo ser concebido como uma prática concreta sujeita a transformações e não como uma atividade mental abstrata, pautada num suposto funcionamento cognitivo invariante. As ações produzem sujeitos e mundos; as práticas produzem efeitos. Diferentes práticas produzem diferentes funcionamentos cognitivos, o que implica na formação de diferentes sujeitos e mundos. Outro aspecto importante é que as práticas nascem num contexto que as marca sem, contudo, determiná-las. Não são eternas, podendo engendrar, a partir de seu próprio movimento, transformações. Nesse sentido, não podemos perder de vista que a investigação das práticas de estudo é atravessada por muitas outras, como é o caso das práticas de ensino e das relações institucionais que ocorrem no seio da escola e/ou da universidade, além dos dispositivos ou instrumentos utilizados. Desse modo, a ação de estudar não é apenas um meio de aquisição de um saber por um sujeito já dado, mas está inserida numa cartografia social e política mais ampla, produzindo nosso sistema cognitivo e o mundo que habitamos.

Encontramos ressonâncias entre o trabalho Michel Foucault (1995a, b) e a proposta autopoiética-enativa. Segundo Paul Veyne (1998), as práticas consistem no método escolhido por Foucault. Ao invés de partir dos objetos, ele inicia pelas práticas.

Tudo gira em volta desse paradoxo, que é a tese central de Foucault, e a mais original: o que é feito, o objeto, se explica pelo que foi o fazer em cada momento da história; enganamo-nos quando pensamos que o fazer, a prática, se explica a partir do que é feito (Veyne, 1998, p. 257).

O objeto se explica pela prática; não é a prática que é explicada pelo objeto. Nos nossos termos, o estudo se explica pelo estudar. Nossas práticas de estudo não se explicam pelo sistema cognitivo e nem por uma preconcepção do que seja o estudo. Ao contrário, através de nossas práticas, através do estudar, vamos configurando o estudo e o próprio sistema cognitivo do estudante. Para Foucault, as práticas não possuem nada de misterioso ou de oculto, mas são aquilo que efetivamente realizamos, seja através de ações motoras ou comportamentos, seja através de palavras, no caso das práticas discursivas. 
Veyne defende que Foucault não fala de algo diferente daquilo que os demais historiadores falam, apenas o faz de modo singular. Aí reside a novidade de sua contribuição, que se baseia em práticas concretas. Foucault não pergunta o que é a loucura, o poder ou a Medicina, mas investiga as práticas que produzem tais objetos. De modo semelhante, aqui não perguntamos o que é o estudo. $\mathrm{O}$ estudo não é um objeto dado desde sempre, invariante, mas é definido e configurado por práticas, modos de relação e de produção, instrumentos e dispositivos que mudam ao longo da história. Esses são responsáveis pelas diversas objetivações.

Orientado pela prática, o pesquisador desloca sua atenção daquilo que está dado, que parece óbvio e natural, que todos acreditam conhecer, para aquilo que faz existir. Desviase dos objetos supostamente naturais para encontrar práticas, modos de fazer, relações. É preciso ir além do genérico e abstrato para encontrar as diferenças concretas.

Com Foucault, podemos dizer que o estudo é aquilo a que as práticas dão lugar. Ele não existe por si, mas como efeito de modos de relação que vão constituir o estudante e o material de estudo. Colocar o problema desse modo possibilita entender o estudo em sua multiplicidade e evita que cometamos o equívoco de comparar o estudante de ontem com o de hoje. Tendo em vista a noção de práticas, não podemos afirmar que o estudante de hoje estuda mais ou menos, melhor ou pior do que o de ontem. Devemos, antes, analisar as diferenças e discutir os efeitos das diferentes práticas.

Roger Chartier (1996, 1998) estabelece como objeto de estudo as práticas de leitura. Sua motivação são as transformações das formas de escrita e de leitura desencadeadas pelas tecnologias eletrônicas na passagem do século XX para o XXI. Conforme aponta, seu problema não é a leitura ou o livro, mas as práticas de leitura. Sobre os historiadores que, pretendendo fazer história da leitura, falam sobre livros, argumenta: "Falta às enumerações dos livros impressos ou possuídos, uma questão central, a dos usos, dos manuseios, das formas de apropriação dos materiais impressos" (Chartier, 1996, p. 77-78). Assim, a noção de prática introduz concretude ao problema, apontando para a multiplicidade. Através dela, busca fomentar um estranhamento em relação àquilo que é tão imediato que parece jamais ter sido diferente:

Com efeito, por um longo período, a leitura parece não ter colocado qualquer questão: não é ela o resultado mais universalmente partilhado da aprendizagem escolar? Não implica sempre uma relação íntima entre o leitor solitário e o livro ou o jornal que é sua leitura? Uma prática cultural, portanto, mas que naturalmente é a de (quase) todos e para todos idêntica (Chartier, 1996, p. 19).

Com o surgimento dos microcomputadores pessoais, seguidos pela internet, muitos previram o desaparecimento da leitura. Afirmavam que algo essencial da relação leitor-livro seria perdido, comprometendo o sentido do texto. Diante desse cenário, Chartier trouxe uma historicização do problema e tal movimento aproxima-o do método foucaultiano. Chartier defende a tese de que o dispositivo de leitura - livro em rolo, códex ou tela do computador - não é apenas um detalhe sem importância, mas produz constrangimentos. Não se trata, portanto, de uma questão de conteúdo. Não é que o livro como o conhecemos (códex) permita acesso a um conteúdo mais profundo ou que o computador possibilite o acesso a um conteúdo mais amplo. A materialidade do dispositivo livro em códex e do computador produz limitações ou permite movimentações diferentes e, como consequência, os efeitos também são distintos. Vale destacar, conforme visto acima, que Vigotski, através da noção de ação mediada, já sinalizava esse aspecto (Vygotski, 2000).

A respeito do impacto causado pelo texto impresso, Chartier (1998, p. 9) afirma: “De modo geral, persistia uma forte suspeita diante do impresso, que supostamente romperia a familiaridade entre o autor e seus leitores e corromperia a correção dos textos, colocandoos em mãos 'mecânicas' e nas práticas do comércio". Tal afirmação chama atenção, na medida em que revela um receio em relação ao impresso semelhante àquele que experimentamos na atualidade em relação ao texto eletrônico. Diante das transformações, é preciso seguir adiante e não se deixar paralisar por uma atitude nostálgica. A tese de Chartier 
nos parece interessante justamente porque, ao invés de privilegiar um tipo de dispositivo de leitura em detrimento dos demais, defende que todos possuem, ao mesmo tempo, limitações e aberturas. A história das práticas de leitura seus usos, manuseios, formas de apropriação e leitura do material impresso - não se faz sem que se leve em consideração a materialidade dos suportes de leitura. Compara o leitor da Antiguidade, que lê nos papiros, com o leitor da tela de computador, e afirma:

De um lado, o leitor da tela assemelha-se ao leitor da Antiguidade: o texto que ele lê corre diante de seus olhos; é claro, ele não flui tal como o texto de um livro em rolo, que era preciso desdobrar horizontalmente, já que agora ele corre verticalmente. De um lado, ele é como o leitor medieval ou o leitor do livro impresso, que pode utilizar referências como a paginação, o índice, o recorte do texto. Ele é simultaneamente esses dois leitores. Ao mesmo tempo, é mais livre. O texto eletrônico lhe permite maior distância com relação ao escrito. Nesse sentido, a tela aparece como ponto de chegada do movimento que separou o texto do corpo (Chartier, 1998, p. 13-16).

Comparando o leitor do livro em códex com o leitor do livro eletrônico, aponta:

O leitor do livro em forma de códex coloca-o diante de si sobre uma mesa, vira suas páginas ou então o segura quando o formato é menor e cabe nas mãos. O texto eletrônico torna possível uma relação muito mais distanciada, não corporal. [...] Como o computador, a mediação do teclado, que já existia com a máquina de escrever, mas que se amplia, instaura um afastamento entre o autor e seu texto (Chartier, 1998, p. 13-16).

Um aspecto importante da análise de Chartier é que ela é propositiva e sugere um modo de intervenção. Consciente de que não se pode voltar atrás na história, sugere que nos apoiemos sobre as práticas de leitura consideradas de menor legitimidade, de modo a conduzi-las por outros caminhos (Chartier, 1998, p. 103-104).

Embora exista uma estreita ligação entre leitura e estudo, as práticas de estudo não se resumem às práticas de leitura. É preciso avançar com Chartier. Reencontramos aqui a ideia de que a noção de prática traz concretude aos objetos de pesquisa, revelando sua multiplicidade. Nesse sentido, Foucault e Chartier se aproximam. Chartier chama atenção para a importância dos dispositivos. O formato de apresentação dos conteúdos interfere na produção de efeitos, seja porque restringe movimentos, seja porque abre novas possibilidades. Portanto não existem práticas certas ou erradas. Porém, não devemos ficar indiferentes diante das práticas e sim avaliar sua potência e sua possível limitação. $\mathrm{O}$ caminho não parece ser negar, menosprezar ou simplesmente exaltar as práticas em ação, mas explorar de perto seus desdobramentos e analisar sua possível composição. Assim procuraremos fazer em relação às práticas de estudo.

\section{Investigando práticas de estudo com estudantes de Psicologia ${ }^{2}$}

\section{Metodologia}

Nossa experiência didática com estudantes de Psicologia e a observação de seus modos de estudar levaram à formulação do problema. Bill Green e Chris Bigun (1995), pesquisadores australianos que desenvolvem pesquisas no contexto dos estudos culturais da Educação, também nos inspiraram. Eles nos provocam: "Existem alienígenas em nossas salas de aula?" (Green \& Bigun, 1995, p. 211). Mas quem são os alienígenas, perguntam, nós, os professores, ou eles, os alunos? As perguntas proliferaram: Será que se trata apenas de bons e maus alunos? De estudar ou não estudar? Um estranhamento se fazia sentir e insistia. Sentíamos a necessidade de conhecer melhor os estudantes com os quais nos relacionávamos. Que modos de conhecer, aprender e estudar estavam em jogo. Dessa maneira, sem perder de vista o fato de que as práticas de estudo se produzem na confluência de muitas outras práticas, nos dedicamos a investigá-las por meio de entrevistas com os estudantes.

As entrevistas seguiram a técnica da entrevista de explicitação (Vermersch, 2000), cujo objetivo é auxiliar na verbalização da ação cognitiva efetuada. Ela se ocupa do como dos processos e não do porquê das atividades. No caso da nossa pesquisa, a ideia foi acessar como os estudantes estão estudando e não 
o que eles pensam sobre o estudo. A técnica nos orienta a trabalhar com a descrição de uma experiência de referência. Em nossas entrevistas procuramos obter inicialmente algumas informações gerais sobre as práticas de cada estudante como, por exemplo: O que costuma motivar você a estudar? O estudo é (ou tem) uma rotina? Como? Em seguida nos concentramos em uma experiência de estudo específica, escolhida pelo voluntário, e buscamos explicitá-la. Vale ressaltar que, assim como a entrevista semiestruturada, a entrevista de explicitação não possui roteiro rígido, mas busca, através de questões abertas, levar o entrevistado a uma posição de fala encarnada. A ideia é que o entrevistador possa auxiliar o entrevistado a ir além da posição de fala abstrata e genérica e a voltar à experiência concreta de uma certa situação de estudo, guiando-o para que tenha acesso às atitudes e aos gestos cognitivos até então implícitos e pré-refletidos, habitualmente não notados.

As entrevistas foram realizadas entre setembro e dezembro de 2008 com voluntários de quatro instituições de ensino superior do município do Rio de Janeiro: duas públicas - Universidade Federal do Rio de Janeiro e Universidade Estadual do Rio de Janeiro - e duas privadas - Pontifícia Universidade Católica e Universidade Veiga de Almeida. Em cada instituição foram realizadas no mínimo quatro entrevistas, o que nos levou a um total de 15 entrevistas transcritas e analisadas. A opção de variar as instituições, bem como de mesclar públicas e privadas, teve por objetivo diversificar a amostra e evitar que particularidades institucionais causassem um viés indesejável na pesquisa. A amostra contou com estudantes do primeiro ao nono período. Numeramos aleatoriamente as entrevistas de 1 a 15, gerando um código de identificação para cada uma, que vai do E1 ao E15. É por meio desse código que elas serão identificadas ao longo do artigo.

O recrutamento de voluntários e as entrevistas foram realizados após autorização das instituições envolvidas. Antes de cada entrevista, a pesquisa foi explicada aos voluntários e as dúvidas esclarecidas através do Termo de Consentimento Livre e Esclarecido. A pesquisa foi aprovada pelo comitê de ética da Escola de Enfermagem Ana Nery da Universidade Federal do Rio de Janeiro em 27 de maio de 2008 (protocolo 32/08).

\section{Resultados e discussão}

O incontornável uso do computador-internet nas práticas de estudo contemporâneas

O principal elemento que apareceu nas entrevistas foi a importância que o dispositivo computador-internet assume nas práticas de estudo contemporâneas. Localizamos em todos os relatos a presença do computadorinternet, o mesmo não acontecendo com livros, livraria e biblioteca. Dizendo de outro modo, se antes a biblioteca e a livraria eram locais incontornáveis para o estudo e a pesquisa, hoje o computador ligado à internet tem ocupado esse espaço. Citamos algumas falas:

Eu perdi esse hábito de ir na livraria primeiro. Eu primeiro vou na internet, pra depois ir na biblioteca, pra depois ir na livraria (E5). Bom, eu preciso saber o nome do autor, da pessoa que escreveu o texto, aí pode ser que eu vá à biblioteca. Mas eu acho que não. Eu boto no Google, porque ali aparece os livros que esse autor [...] Antes de vir pegar o livro aqui na biblioteca eu vou tá lendo sobre o autor ou vendo outros livros que ele escreveu [...] Sempre é a internet primeiro, ver o que está sendo falado sobre o assunto. [...\} É tipo uma garimpada antes (E11).

Localizamos aí uma mudança importante. O levantamento e a busca por material de estudo na contemporaneidade envolvem realizar um deslocamento virtual, mais do que físico. Todo ou quase todo o trabalho de pesquisa de textos pode ser feito sem sair de casa, bastando um computador conectado à internet. Verificamos que tal fato tem potencializado o acesso à informação e incentivado a realização de pesquisas na rede, fazendo nascer o que nomeamos política cognitiva desejosa de saber (Sancovschi \& Kastrup, 2013).

Algumas falas revelaram que o acesso à informação não é necessariamente uma vantagem, nem garante sucesso na produção de conhecimento. Uma estudante relata sua dificuldade em articular as ideias em meio a tanta informação:

Eu fui para o computador, abri o arquivo que já tinha a metodologia, né? Já tinha o espaço para a introdução. Abri, foi a primeira coisa que eu fiz - foi abrir aquele arquivo. Depois eu deixei meu e-mail aberto, abri o Google. 
[...] Porque o arquivo estava no e-mail. Aío Google, aí digitei várias formas: 'tarefa de seleção de Wason e contrato social'; 'contrato social e Wason'; 'artigos acadêmicos sobre tarefa de seleção de Wason'; Ida Cosmos, não sei o quê, o nome dos autores que o professor tinha indicado. Fui abrindo várias janelas. Aí fui lendo: 'Ah! Isso serve; isso não serve; isso serve; isso não serve'. Aí deixei abertos alguns artigos e fui tentar montar o texto. Não me saí muito bem porque eu estava muito confusa com algumas coisas na minha cabeça, porque era muita informação. Às vezes me dá uma agonia quando tem informação demais. [...] E me deu agonia, porque, assim, o que a professora tinha me dito era que tinha a tarefa de seleção de Wason, que tinha um cara que tinha inventado isso, que não sei o quê, que tinha testado e que tinha essa Ida Cosmos, que tinha feito isso com o contrato social. Só que nesse meio do caminho tinham vários autores que fizeram a tarefa de seleção de Wason com várias outras variações. [...] Então várias coisas no meio do caminho. Então eu enlouqueci quando eu comecei a ler tudo: 'Putz! Como é que eu vou explicar isso tudo em um texto de duas páginas?' [...] Eu fiquei doida. Aí, assim, fiz um parágrafo tipo iniciando assim, jogando, resumindo assim: 'Ah, os seres humanos são racionais, não sei o quê e tal. Existe... Como funciona a lógica humana, não sei o quê', levantando o problema (E9).

Perdida em meio à quantidade de informações encontradas, sem conseguir dar conta de elaborar uma síntese, sentindo-se incapaz de tecer uma análise de todo aquele material, a estudante desiste, abandona a tarefa e a passa adiante para um colega:

Mandei para a $N$ [colega que deveria fazer o texto]: 'N, toma aqui que o filho é teu!' Aí ela construiu, me mandou de volta e eu refiz o que ela fez, porque algumas coisas que ela fez estavam meio desencadeadas, faltavam coisas, aí eu fui completando. Aí a gente levou para a professora, ela escreveu... riscou algumas coisas, escreveu outras (E9).

Como a internet acelera a velocidade da busca e encurta as distâncias, potencialmente se tem chances de encontrar coisas novas e diferentes daquilo que poderia inicialmente ter sido definido como importante e interessante. Porém, o revés da moeda é a dificuldade em deter-se e concentrar-se no estudo dos inúmeros textos acessados. No caso acima, a grande quantidade de material foi sentida como algo que gerou "agonia", revelando certo sofrimento. Outro aspecto que chama atenção é que também no que diz respeito aos estudos os encontros virtuais têm aumentado, em detrimento dos encontros físicos, concretos e presenciais com outras pessoas como colegas, professores, monitores e bibliotecários.

A análise dos relatos nos permitiu perceber diversas maneiras de usar o dispositivo computador-internet. Para alguns poucos alunos, a presença do computador-internet representa uma dificuldade. Os estudantes se referem ao excesso de estimulação e a certa tendência à distração, percebidos como inerentes ao dispositivo. Para outros, o uso do computadorinternet integra-se perfeitamente à sua rotina, abrindo inclusive para novas práticas, como é o caso do estudo em circulação. Por estudo em circulação entendemos o tipo de prática desenvolvida por alguns alunos, como no caso de E9, narrado acima. Vale destacar o papel central das novas tecnologias da informação e comunicação nesse tipo de prática. Entre os dois extremos existem muitos estudantes que vão experimentando e se transformando em suas práticas e, ao mesmo tempo, transformando seus estudos.

Algo que nos chamou atenção foi perceber que não é raro que o computador esteja ligado numa situação de estudo sem que necessariamente esteja sendo usado para esse fim. Em função das redes sociais, percebemos que a questão do computador-internet estar ou não sendo usado para estudar torna-se complexa. E2, por exemplo, narra um episódio em que estava estudando para uma prova de Fisiologia enquanto seu computador estava ligado. De repente, seu amigo de turma avisou através do MSN que outro garoto havia postado na comunidade do Orkut uns slides que ele havia pegado na internet justo sobre o mecanismo que era o tema da prova. Nesse momento, o computador e a comunicação virtual deixaram de ser apenas diversão e/ou distração para entrar no circuito daquilo que estava sendo estudado. Citamos um trecho:

Por exemplo, nesse dia que eu descobri esse vídeo no Orkut, eu tava com o Orkut aberto, era... não me lembro se era véspera da prova... Não faltavam acho que tipo dois dias para prova, assim. Aí o menino me mandou o link. Então por acaso eu estava 
com o Orkut aberto e naquele mesmo momento eu já utilizei para uma coisa que aparentemente eu não ia usar. [...] Serviu para eu adicionar no resumo que estava fazendo (E2).

Destacamos que essa prática aponta para mais um exemplo do estudo em circulação.

Quando nos concentramos sobre a elaboração e, principalmente, a redação de trabalhos, surgem outras consequências das práticas de estudo que funcionam a partir do acoplamento cognição-computador-internet. Esse é o caso da escrita por fragmentos e composição por partes. Trata-se do famoso corta-e-cola que, de expressão relativa a comandos do computador, tornou-se uma gíria entre os estudantes. Cada vez mais fazer trabalho assemelha-se à construção não linear de um quebra-cabeças, cuja figura vai sendo definida à medida em que os pedaços vão sendo encontrados, recortados e colados:

Eu vou, boto lá... Sabe aquela coisa bem básica? "Percepção", aí leio, vou lendo, normalmente eu copio e colo o que eu acho que me interessou e vou jogando, vou jogando. Depois que eu acho que joguei bastante coisa interessante, eu leio aquilo tudo. Sempre jogo assim e sei mais ou menos de que site o que eu tirei o que, né? Para não dividir também, senão depois eu vou, quando eu vou escrever eu não sei mais o que eu tirei de cada site. Aí eu leio, leio aquilo tudo, aí eu acho "pô, já dá para escrever suficiente". Aí às vezes eu uso... às vezes até a estrutura como base, às vezes quando eu acho que não vai me ajudar, eu abro outra [janela] e vou fazendo tudo de novo, vou escrevendo, escrevo do meu jeito, assim quando a estrutura que sobrou ali for muito ruim (E3).

Vejamos também o relato do estudante sobre os constrangimentos da leitura e do estudo na tela do computador, que suscitam certa dificuldade na elaboração do pensamento:

Eu acho que no computador não tem dificuldade de você ler as linhas, acho que é a mesma coisa. Mas eu acho que a questão de você ficar voltando no texto, de você elaborar um pensamento em cima do texto é mais fácil no papel. Até porque é cansativo você ficar no computador lendo várias vezes a mesma coisa - para mim é cansativo. Então no papel é menos cansativo. É chato você ler um texto várias vezes - eu não gosto muito -, mas às vezes é necessário. Aí você, no papel, você volta aquilo. $E$ eu acho que também tem a ver um pouco com diagramação, porque na tela você tem aquele papel ali e você geralmente está vendo só uma parte do texto. Na folha você já está vendo o texto um pouco mais completo, você tem um raio de visão maior do que no computador. E aí você tem como marcar mais também nesse sentido: estou lendo uma coisa aqui e isso se relaciona com outra... Às vezes eu faço seta de uma coisa para outra, acrescento coisas que são... Se você botar no computador, por exemplo, uma nota de página, um negócio de rodapé, você vai ter que descer aquele negócio todo para você ver a sua nota. Na folha não, tá ali, um negócio mais... acho que é uma gestalt mais completa. Talvez tenha a ver com isso (E8).

Segundo o estudante, embora o estudo na tela não prejudique o ato de ler, cria dificuldades em relação ao pensamento. A releitura, as marcações, as visualizações das notas de rodapé tornam-se mais difíceis quando se utiliza a barra de rolagem do computador como mediador. Interessante notar como o pensamento se apoia menos na prática da leitura linear do que nas articulações entre passagens do texto. A articulação refere-se aqui tanto à percepção global produzida pelo movimento exploratório dos olhos quanto às marcações manuais que concorrem para a construção de um segundo texto, mais resumido e personalizado. Isso significa que a manipulação concreta do texto durante as práticas de estudo concorre para a abertura de diferentes camadas de sentido, permitindo uma maior apropriação e elaboração do material estudado.

Alguns entrevistados observam que a impressão do texto pode ser uma estratégia interessante, possibilitando uma leitura no papel que complementaria a leitura na tela:

É chato, não gosto muito de ler no computador não. Assim, eu fico naquela: preservar as árvores ou meu conforto? Porque, assim, eu prefiro imprimir, ler, marcar, não sei o quê e tal. Mas às vezes é mais rápido tá no computador porque eu já vou lendo e escrevendo ao mesmo tempo; lendo, recortando, colando, fazendo as coisas ao mesmo tempo. Então às vezes é um 
trabalho mais rápido se eu fizer direto no computador, mas é um trabalho mais bem feito se eu imprimir, marcar, organizar. Então às vezes é questão de tempo mesmo. Se eu tiver mais tempo eu imprimo, leio e tal, quando eu tenho menos tempo eu faço direto no computador (E9).

A fala revela certo dilema: imprimir ou não imprimir. A referência à questão ecológica pode significar uma preocupação real ou uma simples brincadeira. De todo modo, percebemos como questões que talvez não façam sentido para gerações anteriores passam a atravessar e conformar as práticas de estudo hoje. Novamente comparece uma análise que aponta para certo limite do estudo na tela e o possível benefício da utilização de práticas de estudo complementares - no caso, o texto na tela e também o texto impresso.

Outro ponto levantado na fala anterior e que verificamos atravessar de maneira importante as práticas de estudo contemporâneas é a questão do tempo ou, antes, a experiência da falta de tempo. Esse ponto encontra ressonância com a velocidade e as possibilidades de aceleração cognitiva criadas pelas novas tecnologias. É interessante notar como os estudantes têm criado estratégias para driblar a falta de tempo:

A vida de estudo é você saber lidar com isso sim. É você saber o que... é você escolher o que é que você vai ler, determinada coisa, é... às vezes é você escolher o que é que é melhor: se é você assistir determinada aula, ou você em casa descansar ou mesmo estudar, é... ou até mesmo você conciliar: o que é que é mais importante é você assistir a determinada aula de uma disciplina, ou assistir uma palestra, um evento tal no mesmo horário (E7).

É possível ponderar que escolhas sempre existiram na vida dos estudantes e em suas práticas de estudo. Todavia, ao escutar os estudantes de hoje percebemos haver algo da ordem do excesso, de uma superlotação de tarefas, que precisa então ser gerenciada. Essa situação encontra ressonância na vida dos próprios professores e nos faz pensar sobre as políticas acadêmicas e científicas, que têm atravessado as práticas de estudo e de ensino na atualidade (Kastrup, 2010). Cada vez mais exige-se dos professores pesquisadores a produção e divulgação de seus trabalhos, seja na forma de artigos, palestras ou eventos, produzindo, ao mesmo tempo, a demanda do público estudantil. Para além da necessidade de divulgação dos trabalhos científicos, parece estar em jogo certa exigência de performance, que tem afetado professores e estudantes (Sancovschi, 2010).

Assim, o problema do tempo articula-se à questão da performance, sendo desdobrada e afetando as práticas de estudo de diversas formas:

Quando eu uso livro, eu sinto que tenho... É, eu sinto que tenho mais autoridade, eu sinto que eu li lá, na fonte mesmo, então eu posso dizer, até certo ponto, que o que eu tô falando é certo. E quando eu leio tipo uns textos avulsos e tal, é mais pra cumprir um objetivo. [...] Tipo eu leio o texto do professor pra ele... pra responder a prova dele. [...] Mas... é, normalmente acho que eu aprendo mais lendo os livros assim sem compromisso, sabe? [...] Eu acho que dentro do livro tem uma diferença que é... que você tem mais articulação, sabe? Às vezes ele fala, por exemplo: "conceito tal, que vai ser explicado mais adiante". Também no livro você, por exemplo, ver que aquele texto que você tá lendo tava inserido numa unidade maior que tratava sobre outros assuntos diretamente relacionados com ele e tal. Acho que, geralmente, quando você quer aprender um conceito específico assim, realmente é melhor texto avulso, mas para entender melhor a teoria, e é por isso que eu sinto que eu aprendo mais quando eu leio no livro, eu acho que é interessante você ler as coisas no livro assim. Talvez até ler um livro ou outro inteiro. Às vezes eu leio uns livros de Psicologia inteiros, aos pouquinhos, assim (E4).

Este estudante reserva ao livro um lugar em seu estudo. No entanto, ressalta que o livro só é utilizado quando o estudo não possui um objetivo predefinido, ou seja, quando não visa realizar uma tarefa específica, como fazer uma prova. Reconhece no livro um dispositivo que possibilita um estudo mais profundo e interessante, na medida em que permite um maior número de articulações. Dependendo da situação, ele pode ser preterido ou coexistir com a leitura de textos avulsos, quando o estudo é voltado para a realização de tarefas específicas e visa uma performance. Nesse sentido, as práticas de estudo que promovem 
a composição e a coexistência de diferentes dispositivos parecem constituir um caminho fecundo.

\section{Conclusão}

Conforme vimos com Vygotski (2000) e Chartier (1996, 1998), pesquisar as práticas dos estudantes de Psicologia na contemporaneidade passa necessariamente pela análise dos dispositivos utilizados e de seus respectivos constrangimentos. Os dispositivos não são detalhes sem importância, mas participam ativamente das práticas e da configuração da cognição.

A partir das falas dos alunos de Psicologia fica evidente o quanto o uso do computadorinternet participa das práticas de estudo na contemporaneidade. Novos acoplamentos dão lugar a novos hábitos. As buscas e o levantamento bibliográfico envolvem antes a navegação pela internet que as idas às bibliotecas e/ou livrarias. Isso tem incentivado, por um lado, a pesquisa, potencializando o acesso e a manipulação de informações. Porém o acesso à informação não é sinônimo de construção de conhecimento. Os próprios estudantes observam a diferença entre ser capaz de buscar informações e articular ideias. Por outro lado, tal prática pode estar diminuindo os encontros físicos e presenciais com outros estudantes, tornando a troca de ideias e a ajuda recíproca restrita às trocas de mensagens virtuais. Percebemos também que se pratica outra maneira de trabalhar em grupo. Trata-se do estudo em circulação, que se vale das possibilidades criadas pelo computador-internet e suas ferramentas. $\mathrm{O}$ trabalho elaborado por uma única pessoa também tem sido afetado e transformado. A fragmentação e a composição de partes têm se apresentado como características marcantes dos modos contemporâneos de escrita e elaboração de trabalhos acadêmicos. Há narrativas que destacam que o acoplamento da cognição com o computador-internet produz certa dificuldade de pensamento seja porque é cansativo ficar indo e voltando no texto na tela, seja porque o computador não favorece as articulações entre as partes e uma apreensão global do texto. Todavia, parece que hoje é quase impossível estudar sem esse dispositivo. Além disto, a questão do tempo, ou antes, a experiência da falta de tempo nos dias atuais parece combinar-se de maneira bastante eficaz com o computadorinternet, dando conta também da exigência de performance.

O problema dos livros virtuais (e-books) demandaria uma investigação específica e detalhada, que não foi realizada por não ter comparecido na fala dos estudantes. Foi possível perceber que os livros físicos, em códex, perderam espaço nas práticas de estudo. É certo que antes mesmo dos computadores ocuparem o lugar de dispositivo incontornável que possuem na atualidade, a partir da década de 1970 e sobretudo na de 1980, as chamadas "xerox" já ameaçavam o destaque e a hegemonia dos livros 3 . Porém, as xerox ainda eram partes de livros, podendo levar a eles. De alguma maneira, o livro ainda era a principal referência para os estudantes. Isso talvez esteja sendo deixado de lado na atualidade. Hoje a leitura de livros inteiros aparece como uma prática minoritária. Os professores não exigem e os alunos, por sua vez, também não buscam ir além do texto que foi indicado e disponibilizado na pasta da xerox. As práticas de ensino também concorrem para a produção das práticas de estudo. Embora não seja o foco de nossa análise, é importante não perder de vista essa questão, que abre para um estudo futuro.

Ao abordar o problema do estudo a partir da noção de prática vemos que o estudo comporta múltiplas formas, que estão a todo momento se reinventando. Certo, errado, verdadeiro, falso não são adjetivos que deem conta do problema. Não cabe perguntar se o estudante de hoje é melhor ou pior que o estudante de ontem. Ao invés de tecer julgamentos sobre as novas gerações, devemos investigar as singularidades das formas contemporâneas de conhecer e estudar. Evitemos julgar, classificar, diagnosticar, patologizar. Conforme afirma Chartier (1998), referindo-se às práticas de leitura, ao invés de condenar ou recusar as práticas existentes, é preciso compor com elas no sentido de produzir novos desdobramentos. Dessa maneira começamos a enfrentar o desafio de trabalhar com as composições, experimentando as potências e resistências de uma lista aberta de dispositivos cujos desdobramentos podemos ajudar a fazer nascer. 


\section{Beatriz Sancovschi}

Doutora em Psicologia pelo Programa de Pós-Graduação em Psicologia da UFRJ. Professora Adjunta da Universidade Federal do Rio de Janeiro, Rio de Janeiro - RJ. Brasil.

E-mail: beatrizsancovschi@gmail.com

\section{Virgínia Kastrup}

Doutora em Psicologia Clínica pela PUC-SP. Professora Associada da Universidade Federal do Rio de Janeiro, Rio de Janeiro - RJ. Brasil. E-mail: virginia.kastrup@gmail.com

\section{Endereço para envio de correspondência:}

Universidade Federal do Rio de Janeiro. Avenida Pasteur, 250, Pavilhão Nilton Campos, IP. Urca. CEP 22290-902 - Rio de Janeiro, RJ, Brasil.

Recebido 28/08/2012, Aprovado 06/10/2014. 
Referências

Bilimário, H. \& Almeida, L. S. (2008). Aprendizagem auto-regulada: fundamentos e autorganização do programa SABER. Revista Semestral da Associação Brasileira de psicologia escolar e educacional: ABRAPEE, 12(1), 13-22.

Chartier, R. (Org.). (1996). Práticas da leitura. São Paulo: Estação Liberdade.

Chartier, R. (1998). A aventura do livro: do leitor ao navegador. São Paulo: Ed. UNESP.

Foucault, M. (1995a). O sujeito e o Poder. In H. Dreyfus \& P. Rabinow (Orgs.), Michel Foucault: uma trajetória filosófica (pp. 231-249). Rio de Janeiro: Forense Universitária.

Foucault, M. (1995b). Michel Foucault entrevistado por Hubert L.Dreyfus e Paul Rabinow. In H. Dreyfus \& P. Rabinow (Orgs.), Michel Foucault: uma trajetória filosófica (p.253-278). Rio de Janeiro: Forense Universitária.

Gomes, F. S., \& Torres, D. P. (2005). É possível treinar a estudar? Um estudo experimental com alunos de uma escola pública. Revista da Faculdade de Ciências Humanas e Sociais, 1(2), 253-266.

Green, B., \& Bigun, C. (1995). Alienígenas na sala de aula. In T. T. Silva (Org.), Alienígenas na sala de aula: uma introdução aos estudos culturais em educação (pp. 208-243). Petrópolis: Vozes.

Kastrup, V. (2010). Pesquisar, formar, intervir. In Anais do XIII Simpósio de Pesquisa e Intercâmbio da ANPEPP (pp. 169-182). Fortaleza: ANPEPP.

Marton, F., \& Säaljö, R. (1976a). On qualitative diferences in learning: I outcome and process. The British Journal of Educational Psychology, 46(1), 4-11. http://dx.doi. org/10.1111/j.2044-8279.1976.tb02980.x.

Marton, F., \& Säaljö, R. (1976b). On qualitative diferences in learning: II outcome as a fuction of the learner's conception of the task. The British Journal of Educational Psychology, 46(2), 115-127. http://dx.doi.org/10.1111/j.2044-8279.1976. tb02304.x.

Marton, F., Hounsell, D., \& Entwistle, N. (1997). The experience of learning. Edinburgh: Scottish Academic Press.

Maturana, H., \& Varela, F. (1995). A árvore do conhecimento. Campinas: Editorial Psy II.
Piaget, J. (1978). Os Pensadores. São Paulo: Abril Cultural.

Piaget, J. (2001). Seis estudos de psicologia. Rio de Janeiro: Forense Universitária.

Pino, A. (1992). As categorias de público e privado na análise do processo de interação. Education and Society, 13(42), 315-327.

Ronca, P. A. C. (1982). O estudo dirigido. Cortez: São Paulo.

Rosário, P. (2004). (Des)venturas do Testas: estudar o estudar. Portugal: Porto.

Rosário, P., Nuñez, J., \& Pienda, J. (2006). Cartas do Gervásio ao seu umbigo: comprometer-se com o estudar na Universidade. Coimbra: Almedina.

Sancovschi, B., \& Kastrup, V. (2013). Práticas de estudo contemporâneas e a aprendizagem da atenção. Psicologia e Sociedade, 25(1), 193-202. http://dx.doi.org/10.1590/S010271822013000100021.

Sancovschi, B. (2010). Sobre as práticas de estudo dos estudantes de psicologia: uma cartografia da cognição contemporânea. Tese de Doutorado. Instituto de Psicologia, Universidade Federal do Rio de Janeiro, Rio de Janeiro, RJ.

Skinner, B. F. (1972). Tecnologia do ensino. São Paulo: Herder \& USP.

Varela, F. (2003). O reencantamento do concreto. Cadernos de Subjetividade, 1(1), 71-86.

Varela, F., Thompson, E., \& Rosch, E. (2003). A mente incorporada: ciências cognitivas e experiência humana. Porto Alegre: Artmed.

Vermersch, P. (2000). L'entretien d'explicitation. Issy-les-Moulineaux: ESF éditeur.

Veyne, P. (1998). Foucault revoluciona a história. Brasilia: UNB.

Vigotski, L. S. (1998). A formação social da mente. Rio de Janeiro: Martins Fontes.

Vygotski, L. S. (2000). Obras escogidas III. Madrid: Visor. (Trabalho original publicado em 1931). 